\title{
Chlamydia trachomatis as a probable cofactor in human papillomavirus infection in aboriginal women from northeastern Argentina
}

\begin{abstract}
Objectives: High-risk types of human papillomavirus (HPV) are strongly associated with cervical cancer (CC), and Chlamydia trachomatis (CT), the most frequent sexually transmitted bacterial infection (STBI) worldwide, seems to be a risk factor for HPV infection and for CC. It is also known that both agents are more prevalent in vulnerable communities where lack of adequate primary health care is a cause for concern. The aim of this work was to determine the impact of CT and HPV infections in women belonging to an isolated aboriginal population (Pilaga community) from a poor region in Northern Argentina (province of Formosa). For this purpose, a cross-sectional study was performed in all sexually active Pilaga women, who attended a local community-based gynecological health screening project. The polymerase chain reaction (PCR) method on a cervical brush specimen was used to detect both agents. Results: A total of 227 women (20\% of the total female population of the Pilaga community) were studied and the overall prevalence was $26.4 \%$ for CT, $46.7 \%$ for HPV and $16.3 \%$ for concurrent infection. CT infection was higher in HPV DNA positive (34.2\%) than in HPV DNA negative women (19\%; OR: $2.22 / 95 \% \mathrm{CI}=1.16-4.28 / \mathrm{p}=0.009$ ) and the most prevalent HPV types were HPV-16 (19.4\%), 6 and 18 (5.3\%), 58 (3.5\%) and 33 (3.1\%). Conclusions: The prevalence of CT and HPV observed in Pilaga women are among the worst registered in Latin America. Also, data collected suggest that chlamydial infection may play an important role in the natural history of HPV infection. On this respect, we propose that the association between these two agents seems to be more related to a mutual potentiation than to the fact that they share a common route of transmission.
\end{abstract}

Keywords: Chlamydia trachomatis; papillomavirus infections; indigenous population; uterine cervical diseases.

\section{INTRODUCTION}

Chlamydia trachomatis (CT) is the most frequent sexually transmitted bacterial infection (STBI) worldwide, with an estimated 89 million new cases per year. ${ }^{1,2}$ Up to $70 \%$ of such infections are asymptomatic and the detection of cases has an important epidemiological implication, because the main consequences (infertility, ectopic pregnancy, pelvic inflammatory disease and perinatal infections) of symptomatic and asymptomatic infections are often identical. ${ }^{2,3}$ Although many authors refer to an association between CT infection and dysplastic or neoplastic cervical atypia, epidemiological data have not yet provided consistent evidence about its real implication in cervical cancer (CC) development. ${ }^{4-6}$ However, the asymptomatic nature of CT infection, its long-term persistence in the absence of treatment, and its capability of inducing metaplasia and chronic inflammation are well-defined characteristics to strongly consider this bacteria as a potential cofactor for high-risk persistent HPV infection (the main proven cause of CC)..$^{7-9} \mathrm{HPV}$ genital infection is highly frequent worldwide and its prevalence in the general population ranges from $2-44 \%$ depending on the region of the world. ${ }^{10}$ However, it is known that most HPV infections are transient and only a small proportion of women with high-risk persistent HPV infection will develop CC. ${ }^{11-13}$ Therefore, numerous cofactors that might promote virus persistence or enhance its oncogenicity have been studied in recent decades to better understand the oncogenic process. ${ }^{14,15} \mathrm{CT}$ is one of these cofactors. ${ }^{4,8,9}$

The annual mortality rate for CC in Argentina is $7.8 / 100,000$ women, but this rate is three times higher in the northeastern region
Authors

Gerardo Daniel Deluca

Jorge Basiletti ${ }^{2}$

Eduardo Schelover ${ }^{3}$

Nicolás Díaz Vásquez

José Mario Alonso ${ }^{5}$

Héctor Marcelo Marín

Raúl Horacio Lucero

María Alejandra Picconi

${ }^{1} \mathrm{PhD}, \mathrm{MSc}$, Professor, Faculty of Medicine, Northeast National

University, Corrientes, Argentina ${ }^{2}$ Biochemist; Researcher,

Oncogenic Virus Service, Nationa

Reference Laboratory on Human

Papillomavirus, National Institute

of Infectious Diseases "Carlos G.

Malbrán", Buenos Aires, Argentina

${ }^{3} \mathrm{MD}$, Pathologist, Institute of

Regional Medicine, Northeast

National University, Chaco,

Argentina

${ }^{4} \mathrm{MD}$, Gynecologist, Institute of

Regional Medicine, Northeast

National University, Chaco,

Argentina

${ }^{5} \mathrm{PhD}$, Head of the Immunology

Service, Institute of Regional

Medicine, Northeast National

University, Chaco, Argentina

${ }^{6}$ Biochemist, Researcher, Molecular

Biology Laboratory, Institute of

Regional Medicine, Northeast

National University, Chaco,

Argentina

${ }^{7}$ Biochemist, Head of the Molecular Biology Laboratory, Institute of

Regional Medicine, Northeast

National University, Chaco,

Argentina

${ }^{8} \mathrm{PhD}$, Head of the Oncogenic

Virus Service, National

Reference Laboratory on Human

Papillomavirus, National Institute

of Infectious Diseases "Carlos G.

Malbrán”, Buenos Aires, Argentin

Submitted on: 05/14/2011

Approved on: 07/08/2011

Correspondence to:

Gerardo Daniel Deluca

Roldán 1307 (CP:3500)

Resistencia,

Chaco, Argentina

delucagd@gmail.com

Financial Support: This work was partially funded by the General Secretariat of

Science and Technology of

National Northeast University, Argentina.

We declare no conflict of interest.

(ㅇ)2011 Elsevier Editora Ltda. All rights reserved. 
of the country, ${ }^{16}$ where a wide spectrum of Indian and isolated white communities live in unfavorable socioeconomic and health conditions.

The aim of this study was to determine the prevalence of CT and HPV infections among vulnerable populations of native Indians belonging to the Pilaga community in northern Argentina.

\section{METHODS}

\section{Study population}

This study was nested in a community-based gynecological health screening project for the Pilaga aboriginal people of the central region of Formosa province (northern Argentina). Two hundred and twenty-seven women aged 13-68 years (mean age 30 years), corresponding to $20 \%$ of all sexually active women of the Pilaga Indians in Argentina, were recruited from different aboriginal settlements between March 2007 and March 2009. A standardized questionnaire was used to interview the subjects regarding their clinical history, sexual behavior, cultural habits and socio-economic and living conditions. After providing informed consent, all women were examined by a gynecologist.

The study was reviewed and approved by the Ethics Committee of the Institute of Regional Medicine of Northeast National University, Argentina.

\section{Sample collection and DNA extraction}

Cervical exfoliated cells were collected from all women by sampling the ecto- and endocervix using a wooden spatula for PAP smears and a cytobrush for HPV and CT DNA detection. Cervical cells from the latter were eluted in sterile phosphate-buffered saline (PBS) contained in a tube, and then transported on ice to the processing laboratory. Upon arrival to the lab and after checking the sample container's integrity, the cells of each sample were pelleted by centrifugation and kept frozen at $-70^{\circ} \mathrm{C}$ until processing.

DNA was obtained by treating pellets with $400-700 \mu \mathrm{L}$ of homogenization solution ( $2 \%$ cetyltrimethylammonium bromide-CTAB, $1.4 \mathrm{M} \mathrm{NaCl}, 0.2 \% \quad \beta$-mercaptoethanol, $20 \mathrm{mM}$ EDTA, $100 \mathrm{mM}$ Tris- $\mathrm{HCl} \mathrm{pH}$ 5.0), extracted with chloroform isoamyl alcohol method, then precipitated with absolute ethanol and resuspended in $50-100 \mu \mathrm{L}$ of sterile double-distilled water. All samples were checked to assess DNA quality and integrity by amplifying a known region of the human $\beta$-globin gene (268 bp). The samples negative for the $\beta$-globin test were discarded.

\section{Cytological analysis}

PAP smears were processed and analyzed according to the 2001 Bethesda Classification System. The final diagnosis was based on the worst morphological picture.

\section{CT and HPV DNA amplification}

CT DNA was detected in cervical samples by polymerase chain reaction (PCR) using the KL1/KL2 primers, as previously described. ${ }^{17}$ This primer pair amplifies a $241 \mathrm{bp}$ fragment of the chlamydial multicopy, and a genetically conserved, cryptic plasmid. PCR was performed in a final volume of $20 \mu \mathrm{L}$ using $3 \mu \mathrm{L}$ of DNA sample; $10 \mathrm{mM}$ Tris$\mathrm{HCl} \mathrm{pH}=8.3,50 \mathrm{mM} \mathrm{KCl}, 3.5 \mathrm{mM} \mathrm{MgCl}_{2}, 5 \mathrm{nmol}$ of each deoxyribonucleoside triphosphate (dNTP), $20 \mathrm{pmol}$ of each primer, $1.25 \mathrm{U}$ Taq DNA polymerase (Go-Taq ${ }^{\circ}$ DNA polymerase, Promega, USA). Each amplification reaction was carried out as follows: an initial cycle at $93^{\circ} \mathrm{C}$ for $3 \mathrm{~min}$; 35 cycles of $1 \mathrm{~min}$ at $93^{\circ} \mathrm{C}, 1 \mathrm{~min}$ at $64^{\circ} \mathrm{C}$ and $1 \mathrm{~min}$ at $72^{\circ} \mathrm{C}$ and a final extension at $72^{\circ} \mathrm{C}$ for $5 \mathrm{~min}$. Finally, the PCR products were electrophoresed on a $2 \%$ agarose gel, stained with ethidium bromide (EB) and photographed under UV light.

HPV DNA amplification and typing were conducted using the widely known MY09/11 PCR (450 bp PCR product) followed by the restriction fragment-length polymorphism (RFLP) technique, as previously described. ${ }^{18,19}$ Briefly, the products of MY09/11 PCR were first electrophoresed on a $\%$ agarose gel, stained with EB and visualized under UV light. Then, the amplicons of positive samples were digested by seven restriction enzymes (BamHI, DdeI, HaeIII, HinfI, PstI, RsaI and Sau3AI) in individual microtubes. After that, the RFLP product of each sample was electrophoresed on a 3\% agarose gel, stained with EB, and photographed under UV light. Each restriction pattern was compared with published data to identify the genotype(s) involved.

\section{Statistical analysis}

Continuous variables were categorized, and the risk associated with CT positivity was calculated for each category of a variable, adjusted by age. Univariate analysis was performed for all variables, and multivariate logistic regression analysis was performed in order to identify the independent variables that influence the relative risk of CT positivity $(95 \% \mathrm{CI})$. The association between CT and HPV infections was evaluated in all women regardless of their cytological diagnosis. Data were analyzed using the Epi-Info $^{\mathrm{TM}}$ 3.5.1 Statistical Program (Centers for Disease Control and Prevention, Atlanta, GA) and statistical significance was determined by Fisher's exact test, and p-values $\leq 0.05$ were considered significant.

\section{RESULTS}

The overall prevalence was $26.4 \%$ for CT, $46.7 \%$ for HPV and $16.3 \%$ for concurrent infection. The mean crude prevalence did not significantly differ from the age-adjusted one. The mean frequency of infection, for both agents considered, increased with the severity of cervical lesions; however, this 
was more notorious for HPV infection and particularly for high-risk HPV types. The HPV prevalence estimates were $27.8 \%$ in women with normal pap smear, $46.2 \%$ in women with reactive cellular changes (RCC), $87.5 \%$ in patients with low-grade squamous intraepithelial lesion (L-SIL), and $100 \%$ in patients with high-grade squamous intraepithelial lesion (H-SIL) and CC $(\mathrm{p}<0.05)$ (Table 1).

The prevalence of CT infection was significantly higher among women with positive HPV DNA $(37 / 106=34.9 \%)$ than among those with negative HPV DNA $(23 / 121=19 \%$; OR: $2.28,95 \% \mathrm{CI}=1.20-4.38, \mathrm{p}=0.007)$. This association remained significant when high- and low-risk HPV types were considered separately, as well as infections with one or multi- ple viral types (Table 2). Nevertheless, there was no clear association between age, age at first intercourse, number of lifetime sexual partners or parity and CT infection. Also, we could not evaluate the impact of tobacco or the use of oral contraceptive (OC) because only a minor proportion of women referred to a smoking habit $(3.1 \%)$ and less than $6 \%$ of women had used $\mathrm{OC}$ at some point in life. The socio-economic evaluation of the living conditions in the Pilaga community showed that the majority of participants had completed elementary school education (76.8\%), but only $27.5 \%$ of women had a formal or informal occupation at the moment of the study, $98.3 \%$ had no sanitary latrines in their houses and only $5 \%$ had well water for drinking and cleaning.

Table 1. Chlamydia trachomatis and human papillomavirus infections stratified by grade of cervical status among sexually active women of the Pilaga community

\begin{tabular}{|c|c|c|c|c|c|c|c|}
\hline Cytology & n (\%) & $\begin{array}{c}\text { HPV } \\
\text { positive (\%) }\end{array}$ & p & $\begin{array}{c}\text { High-risk HPV } \\
\text { positive (\%) }\end{array}$ & p & $\begin{array}{c}\text { CT } \\
\text { positive (\%) }\end{array}$ & p \\
\hline $\begin{array}{l}\text { Negative for SIL } \\
\text { or malignancy }\end{array}$ & 36 (15.8) & $10(27.8)$ & & 7 (19.4) & & $8(22.2)$ & \\
\hline RCC & $173(76.2)$ & $80(46.2)$ & & 50 (28.9) & & $47(27.2)$ & \\
\hline L-SIL & $16(7)$ & $14(87.5)$ & 0.015 & $12(75.0)$ & 0.010 & $5(31.3)$ & 0.968 \\
\hline H-SIL & $1(0.4)$ & $1(100)$ & & $1(100)$ & & $0(0)$ & \\
\hline CC & $1(0.4)$ & $1(100)$ & & $1(100)$ & & $0(0)$ & \\
\hline Total & $227(100)$ & $106(46.7)$ & & $71(31.3)$ & & $60(26.4)$ & \\
\hline
\end{tabular}

SIL, squamous intraepithelial lesion; RCC, reactive cellular changes; L-SIL, low-grade squamous intraepithelial lesion; H-SIL, highgrade squamous intraepithelial lesion; ISC, in situ carcinoma.

Table 2. Association between Chlamydia trachomatis and human papillomavirus infections in cervical samples

\begin{tabular}{|c|c|c|c|c|c|}
\hline & \multicolumn{2}{|c|}{$\begin{array}{l}\text { Total of women studied } \\
\qquad(n=227)\end{array}$} & \multicolumn{2}{|c|}{$\begin{array}{l}\text { Women with CT DNA positive } \\
\qquad(\mathrm{n}=60)\end{array}$} & \multirow[b]{2}{*}{ OR $(95 \% \mathrm{CI})$} \\
\hline & $\mathbf{n}$ & $\%$ & $\mathbf{n}$ & $\%$ & \\
\hline HPV- & 121 & 53.3 & 23 & 19 & $1^{\mathrm{a}}$ \\
\hline $\mathrm{HPV}+$ & 106 & 46.7 & 37 & 34.9 & $\begin{array}{c}2.28(1.20-4.38) \\
\quad p=0.007\end{array}$ \\
\hline \multicolumn{6}{|l|}{ HPV+ according to risk group } \\
\hline High-risk types & 71 & 31.3 & 24 & 33.8 & $\begin{array}{c}2.18(1.06-4.49) \\
\quad p=0.021\end{array}$ \\
\hline Low-risk types & 23 & 10.1 & 9 & 39.1 & $\begin{array}{c}2.74(0.95-7.83) \\
\quad p=0.033\end{array}$ \\
\hline Single HPV infections & 78 & 34.4 & 26 & 33.3 & $\begin{array}{c}2.13(1.05-4.32) \\
\quad p=0.022\end{array}$ \\
\hline Multiple HPV infections & 28 & 12.3 & 11 & 39.3 & $\begin{array}{c}2.76(1.04-7.28) \\
\quad p=0.021\end{array}$ \\
\hline
\end{tabular}

${ }^{a}$ Reference group. 


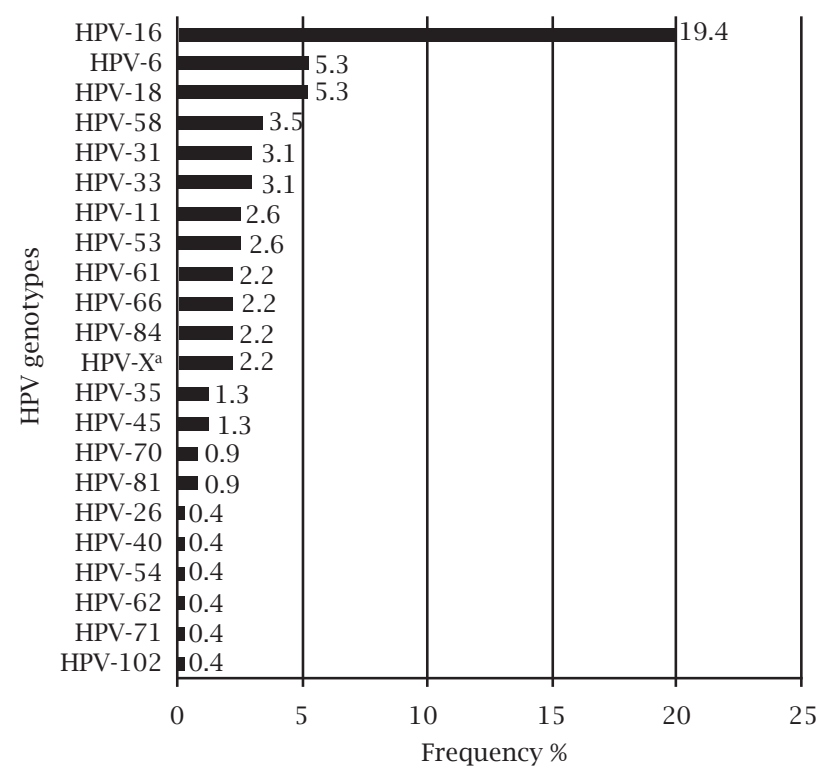

Figure 1: Prevalence of individual HPV types in cervical scrapes among Pilaga women detected by broad-spectrum polymerase chain reaction (MY 09/11 PCR) and a restriction fragment-length polymorphism assay (RFLP).

${ }^{a} \mathrm{HPV}$ genotypes that could not be defined by the RFLP technique.

The individual prevalence for the 21 different detected HPV types is presented in Figure 1. Among the high-risk types, HPV-16 was clearly the most prevalent (44/227; 19.4\%), followed by HPV-18 (12/227; 5.3\%), -58 $(8 / 227 ; 3.5 \%)$, and -31 and -33 (7/227; $3.1 \%)$; while among low-risk type, HPV-6 was the most prevalent (12/227; 5.3\%), followed by HPV-11 (6/227; 2.3\%), and -61 and -84 (5/227; $2.2 \%)$. Taking into account all the types found in this series, the most frequent were, in order, HPV-16, 18, 6, 58 and 33. In addition, 28 infections by multiple HPV types were observed, corresponding to $12.3 \%$ of the total women studied.

According to the data obtained, the only independent variable associated with CT-DNA positivity was concurrent HPV infection.

\section{DISCUSSION}

Despite the numerous logistical and cultural barriers that hindered this work in the Pilaga population, we were able to recruit and study $20 \%$ of the sexually active women of the community.

At large, developing countries seem to have higher prevalence of CT infections. ${ }^{20}$ These nations have values that range from $5 \%$ to $22 \%$ in the general population and can reach peaks as high as $41 \%$ among female adolescents. ${ }^{1,21-24}$ On the other hand, in developed countries, the prevalence levels range from less than $2 \%$ to $8-10 \%$ in general population and from less than $5 \%$ to $20 \%$ among female adoles- cents. ${ }^{1,25}$ In Argentina, many prevalence studies of CT infection have been conducted among women, but these studies have two important shortcomings: (I) most of them used non-standardized populations, different analytical methods to detect CT or only considered symptomatic cases; and (II) there is scarce epidemiological information about populations from northern Argentina, the region with the highest reported clinical diagnosis of STBI of the country. The available data show that prevalence ranges from $1.8 \%$ to $13 \%$ in the general population and from $20 \%$ to $47 \%$ in women with gynecological alterations. ${ }^{20,26-28}$ The overall prevalence of CT found in our study (26.4\%) is clearly the highest reported in Argentina for the general population and is very close to the worst prevalence rates worldwide.

For HPV, the worldwide infection prevalence ranges from $2-44 \%$ in the general population. Once again, developing countries usually have the highest prevalence rates. ${ }^{10}$ A recent worldwide meta-analysis on global HPV prevalence demonstrated an infection rate of $10.4 \%$ for the world and $12.9 \%$ for Latin America, ${ }^{29}$ and HPV-16 was the most common type in both normal and pathological populations. In our study, the overall prevalence of HPV was very high (46.7\%), similar to the values found in developing countries with serious problems with implementing and maintaining a sustainable gynecological health policy. Also, it is comparable with the results obtained by other authors in other indigenous populations of northern Argentina (prevalence ranging from $52 \%$ to $60 \%$ ), but clearly exceeds the mean frequency for populations from the central and southern regions of the country and for Latin American women. ${ }^{10,29,30}$ In relation to the genotypes found, HPV-16 clearly stands out among the 21 different types identified in this work, which coincides with worldwide data and with previous studies on different populations in Argentina. ${ }^{31-34}$ In addition, the four most prevalent HPV types among Pilaga women (HPV-16, $18,6$ and -1$)$ represent $70 \%$ of all infections detected. These are very important baseline data to take into account for future post-vaccination epidemiological surveillance.

It is well-known that CT infection may play a major role in the etiology of cervical intraepithelial neoplasia by facilitating high-risk HPV entrance and persistence. Probably, this is due to the chronic inflammation induced by the bacteria, and to the resistance to cell apoptosis that persistent CT infections appear to confer. In this respect, our data highlight a moderate but significant association between concurrent CT and HPV infection. However, due to the cross-sectional design of this study, it was not possible to determine the primary infection in patients with concurrent $\mathrm{CT}$ and HPV infections. CT and HPV DNA detection by PCR-based assay only indicates an acute or chronic infection in the first case and a transient or persistent HPV infection. Nonetheless, the association between these two agents seems to be more related to a mutual potentiation 
than to the fact that they share a common route of transmission. ${ }^{35}$ In fact, controversial and discordant information exists on this topic, and since the role of CT in the natural history of HPV infection is not sufficiently clear, this particular issue merits further study.

\section{CONCLUSIONS}

The overall prevalence of CT and HPV infections found in this study is very high, even greater than other Latin American prevalences. The epidemiological data obtained in this work referred to a specific population, but numerous small communities exist in a similar situation in northern Argentina. One could then suppose that similar infection rates prevail requiring effective and sustainable health policies to be implemented. In the case of $\mathrm{HPV}$, this is very important in order to prevent CC development. For CT, its control is essential for preventing pelvic inflammatory disease and infertility. Our data may help physicians to prevent diseases in their gynecological practices, particularly when dealing with vulnerable populations.

\section{ACKNOWLEDGEMENTS}

The authors gratefully acknowledge the Pilaga aboriginal community, the health care volunteers of Las Lomitas (Province of Formosa) and Dr. Horacio Lucero for his assistance in HPV-DNA testing.

\section{REFERENCES}

1. World Health Organization. Global prevalence and incidence of selected curable sexually transmitted infections-Overview and estimates [Internet]. Geneva; 2001. Available from: http://www.who.int/hiv/pub/sti/who_hiv_aids_2001.02.pdf

2. Stamm WE. Chlamydia trachomatis infections of the adult. In: Holmes KK, Sparling PF, Stamm WE et al., editors. Sexually transmitted diseases. New York: McGraw-Hill Medical;2008. pp. 575-94.

3. Stamm WE. Chlamydia trachomatis - the persistent pathogen: Thomas Parran Award Lecture. Sex Transm Dis. 2001;28(12):684-9.

4. Smith JS, Bosetti C, Muñoz N, et al. Chlamydia trachomatis and invasive cervical cancer: a pooled analysis of the IARC multicentric case-control study. Int J Cancer. 2004;111(3):431-9.

5. Lehtinen M, Ault KA, Lyytikainen E, et al. Chlamydia trachomatis infection and risk of cervical intraepithelial neoplasia. Sex Transm Infect [Internet]. 2011; Available from: http://www.ncbi.nlm.nih.gov/pubmed/21471141

6. Oliveira M L, Amorim MMR, Souza PRE, et al. Chlamydia infection in patients with and without cervical intra-epithelial lesions tested by real-time PCR vs. direct immunofluorescence. Braz J Infect Dis. 2008;12(4):324-8.

7. Silins I, Ryd W, Strand A, et al. Chlamydia trachomatis infection and persistence of human papillomavirus. Int J Cancer. 2005;116(1):110-5.
8. Smith JS, Muñoz N, Herrero R, et al. Evidence for Chlamydia trachomatis as a human papillomavirus cofactor in the etiology of invasive cervical cancer in Brazil and the Philippines. J Infect Dis. 2002;185(3):324-31.

9. Simonetti AC, Melo JH de L, de Souza PRE, et al. Immunological's host profile for HPV and Chlamydia trachomatis, a cervical cancer cofactor. Microbes Infect. 2009;11(4):435-42.

10. Bosch FX, Burchell AN, Schiffman M, et al. Epidemiology and natural history of human papillomavirus infections and type-specific implications in cervical neoplasia. Vaccine. 2008;26:K1-16.

11. Schiffman M, Castle PE, Jeronimo J, et al. Human papillomavirus and cervical cancer. Lancet. 2007;370(9590):890-907.

12. Kjaer SK, van den Brule AJC, Paull G, et al. Type specific persistence of high risk human papillomavirus (HPV) as indicator of high grade cervical squamous intraepithelial lesions in young women: population based prospective follow up study. BMJ. 2002;325(7364):572.

13. Ho GY, Burk RD, Klein S, et al. Persistent genital human papillomavirus infection as a risk factor for persistent cervical dysplasia. J Natl Cancer Inst. 1995;87(18):1365-71.

14. Almonte M, Albero G, Molano M, et al. Risk factors for human papillomavirus exposure and co-factors for cervical cancer in Latin America and the Caribbean. Vaccine. 2008;26 Suppl 11:L16-36.

15. Drain PK, Holmes KK, Hughes JP, et al. Determinants of cervical cancer rates in developing countries. Int J Cancer. 2002;100(2):199-205.

16. Arrossi S. Proyecto para el mejoramiento del Programa Nacional de Prevención de Cáncer de Cuello Uterino en Argentina. Informe final: Diagnóstico de situación del Programa Nacional y Programas Provinciales [Internet]. 1st ed. Buenos Aires: Organización Panamericana de la Salud, OPS; 2008. Available from: http://www.msal.gov.ar/cancercervico-uterino/pdf/pub64_ops.pdf

17. Mahony JB, Luinstra KE, Sellors JW, et al. Confirmatory polymerase chain reaction testing for Chlamydia trachomatis in firstvoid urine from asymptomatic and symptomatic men. J Clin Microbiol. 1992; 30(9):2241-5.

18. Bernard HU, Chan SY, Manos MM, et al. Identification and assessment of known and novel human papillomaviruses by polymerase chain reaction amplification, restriction fragment length polymorphisms, nucleotide sequence, and phylogenetic algorithms. J Infect Dis. 1994; 170(5):1077-85.

19. Manos MM, Ting Y, Wright DK, et al. The use of polymerase chain reaction amplification for the detection of genital human papillomavirus. Cancer Cells. 1989; (7):209-14.

20. Franceschi S, Smith JS, van den Brule A, et al. Cervical infection with Chlamydia trachomatis and Neisseria gonorrhoeae in women from ten areas in four continents. A cross-sectional study. Sex Transm Dis. 2007; 34(8):563-9.

21. León SR, Konda KA, Klausner JD, et al. Chlamydia trachomatis infection and associated risk factors in a low-income marginalized urban population in coastal Peru. Rev Panam Salud Publica. 2009; 26(1):39-45.

22. Martínez TMA, Reid SI, Arias C, et al. Prevalence of cervical infection by Chlamydia trachomatis among Chilean women living in the Metropolitan Region. Rev Med Chil. 2008; 136(10):1294-300.

23. Rodrigues MM, Fernandes PÁ, Haddad JP, et al. Frequency of Chlamydia trachomatis, Neisseria gonorrhoeae, Mycoplasma genitalium, Mycoplasma hominis and Ureaplasma species in cervical samples. J Obstet Gynaecol. 2011; 31(3):237-41. 
24. Santos C, Teixeira F, Vicente A, et al. Detection of Chlamydia trachomatis in endocervical smears of sexually active women in Manaus-AM, Brazil, by PCR. Braz J Infect Dis. 2003; 7(2):91-5.

25. Wilson JS, Honey E, Templeton A, et al. A systematic review of the prevalence of Chlamydia trachomatis among European women. Hum Reprod Update. 2002; 8(4):385-94.

26. de Cristófano MA, Livellara B, Galli MA, et al. Extent of endemic Chlamydia trachomatis in the metropolitan area of Buenos Aires (Argentina). Enferm Infecc Microbiol Clin. 1997;15(3):134-9.

27. Di Bartolomeo S, Rodríguez M, Sauka D, et al. Microbiologic profile in symptomatic pregnant women's genital secretions in Gran Buenos Aires, Argentina. Enferm Infecc Microbiol Clin. 2001 19(3):99-102.

28. Golijow CD, Abba MC, Mourón SA, et al. Chlamydia trachomatis and human papillomavirus infections in cervical disease in Argentine women. Gynecol Oncol. 2005;96(1):181-6.

29. de Sanjosé S, Diaz M, Castellsagué X, et al. Worldwide prevalence and genotype distribution of cervical human papillomavirus DNA in women with normal cytology: a meta-analysis. Lancet Infect Dis. 2007;7(7):453-9.
30. Clifford G, Gallus S, Herrero R, et al. Worldwide distribution of human papillomavirus types in cytologically normal women in the International Agency for Research on Cancer HPV prevalence surveys: a pooled analysis. Lancet. 2005;366(9490):991-8.

31. Tonon SA, Picconi MA, Zinovich JB, et al. Prevalence of cervical infection by human papilloma virus (HPV) in the Caucasian and Guaraní populations residing in the province of Misiones, Argentina. Rev Argent Microbiol. 2003;35(4):205-13.

32. Picconi MA, Gronda J, Alonio LV, et al. Human papilloma virus in Quechua women from Jujuy with high frequency of cervical cancer: viral types and HPV-16 variants. Medicina (B Aires). 2002;62(3):209-20.

33. Matos E, Loria D, Amestoy GM, et al. Prevalence of human papillomavirus infection among women in Concordia, Argentina: a population-based study. Sex Transm Dis. 2003;30(8):593-9.

34. Sijvarger CC, González JV, Prieto A, et al. Cervical infection epidemiology of human papillomavirus in Ushuaia, Argentina. Rev Argent Microbiol. 2006;38(1):19-24.

35. Verhoeven V, Baay M, Weyler J, et al. Concomitant Chlamydia trachomatis and human papilloma virus infection cannot be attributed solely to sexual behaviour. Eur J Clin Microbiol Infect Dis. 2004;23(9):735-7. 